\title{
AUTOMATED ASSEMBLY PLANNING BASED ON SKELETON MODELLING STRATEGY
}

\author{
H. Bley ${ }^{1}$ and M. Bossmann ${ }^{1}$ \\ ${ }^{\prime}$ Institute of Production Engineering/CAM, University of the Saarland
}

Abstract: Because of intensification of the international market situation the industry is forced to extend the product range and to shorten the period of time between the model changes in order to put new products on the market. Standards that allow generating product and resource variants by creating reusable structures (templates) have to be worked out to support the simultaneous engineering process. The challenge is the parallelisation of the product development and the production planning as far as possible to generate a robust production. In process planning as a part of assembly planning, the assembly processes and their sequence have to be defined and the motion path and speed of an assembly process can be visualized and optimized by Digital Mock-Up (DMU). Realising an early connection between product design and assembly planning new strategies have to be developed.

Key words: Design for assembly, Assembly planning, Simultaneous engineering

\section{INTRODUCTION}

In the Digital Factory [1] assembly planning is supported by collision examinations, ergonomic simulation, process planning, scheduling and material flow simulation. The aim is to support the assembly planning tasks more strongly and to automate routine activities. The assembly planning is based on the bill of materials by which assembly surface matrix, the directed and undirected assembly surface graph as well as the assembly priority graph 
can be created. These planning tasks are based on the final three-dimensional model. That means, planning tasks have to be integrated earlier in the product development process to evaluate the product model in early design phases with regard to the possibility to assemble the product or to initiate design changes in order to avoid cost-intensive assembly processes as shown in figure 1 [2]. So, standards have to be worked out that allow such analysis without generating additional work for the different departments that are involved in the product development process. Ensuring an improved sequence of operations in assembly planning based on basic design information, new strategies for the data transmission have to be installed to solve the interaction tasks realising a stronger connection and a better transparency along the whole product development process.

Therefore milestones along the development process have to be defined in order to generate a frictionless data exchange between the departments that optimise the sequence and parallelisation of operations.

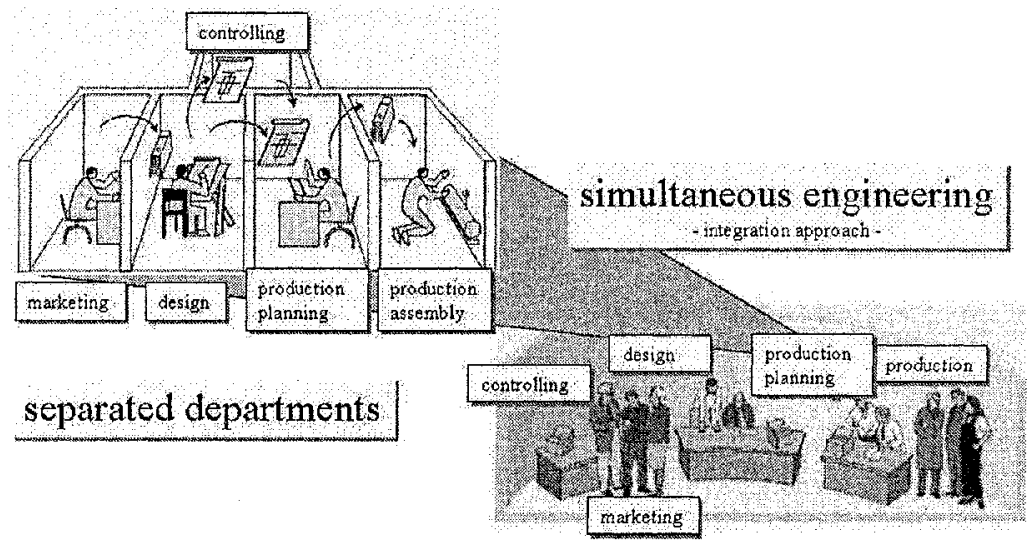

Figure 1. Interdisciplinary Working System to improve the Simultaneous Engineering Process according to $[3,4]$

Normally the design department supplies the assembly planning with the finished three-dimensional model and the bill of materials. Then the assembly department has the task to assemble the product and to transform the design-oriented engineering bill of material (E-BOM) into a productionoriented manufacturing bill of material (M-BOM).

Today, there is no real control loop between product design and assembly planning because often there is no time to review the design by the assembly planning department. The design department should take the assembly of the product into account. So, the product is fixed and the assembly planning department has the task to plan the assembly of the product. The data transfer between the design department and the assembly planning 
department is realised in sequences without real parallelisation, the mentioned departments finish their work completely before the model or other data leave the department. Therefore our aim is to realise an overlapping in time of design and planning work, to install control loops to achieve a better interaction between the different departments. So it is possible to produce cost effective products in a shorter time and with a higher quality. A first important step towards such a development process is the definition of milestones and special data like the function model of the product that have to be transferred to the different departments. Every department has the aim to finish their data for the exchange to climb the next stage in the development process.

In this regard we do not have the aim to produce additional work for the departments, it is our aim to support the departments in routine work such as the data exchange at certain times in a special format for a frictionless data transfer or in other tasks. If there are standardized data formats used for data exchange, it will also be possible to automate the data input. Therefore a stronger and closer contact between the different departments can be realised with the result of an enhanced parallelisation of different work along the development process with the result of a better product transparency as shown in figure 1 ,

\section{FEATURE TECHNOLOGY}

The feature technology [5] offers the possibility to implement such standards and to enlarge the product model with the results of an automated support. At the moment, features are primarily used in design to improve routine activities and to save working time. In this area for example drillings are already represented very well with features.

The drilling types as well as the drilling parameters such as length and diameter have to be selected to fix the geometry. Then, the negative volume will be created und subtracted from the three dimensional product model.

Another advantage of using features is a more structured product model that is able to be enhanced with process information or every other needed information. This additional information can be filtered by a macro to separate the information for each department without burden the different departments with unnecessary information.

The newly developed feature elements are called skeleton elements. These elements characterise the function of the area with simple geometry in different colours $[6,7,8]$. 
Skeleton elements carry their name that represents semantic information. Furthermore the position and the orientation of each element are integrated as a parameter. Specific elements are enhanced with additional parameters to expand the feature with special information about the area to achieve a better product and process description.

These features are integrated into a modern modelling concept called skeleton modelling that allows creating variants by changing parameter configurations [9]. Skeleton modelling can be seen as a template technology for product variants. The skeleton modelling concept has different hierarchy levels: The assembly skeleton level is the topmost level that contains all global parameters and references of the product model. These parameters and references are passed on to the other hierarchy levels such as subassembly skeleton and part skeleton. The undermost hierarchy levels do not pass any parameter and references to other elements or other skeleton models. The functionality of the product is visualised by the skeleton elements what offers a fast transparency for the user without an extraction of the whole product because there is no element hidden by another one.

\section{AUTOMATED ASSEMBLY PLANNING}

Function areas of the product model that are represented by feature elements can be read out by a macro. So, overlapping elements with opposed characters can be found out. These elements represent contact areas of different parts that have to be assembled. Figure 2 illustrates the detection of contact surfaces.

This information can be used to deduce the assembly surface matrix, the undirected and directed assembly surface graph as well as the assembly priority graph. The result is a variety of possibilities to assemble the product model. The aim is an analysis of all assembly sequences to choose the best ones for an automated assembly. Therefore each assembly sequence has to be analysed by a collision check of an automated generated assembly simulation [10]. In the following, it is explained how to generate a kinematical simulation between two parts by using skeleton models with skeleton elements. The feature elements are established in the skeleton model, their information is saved in special areas of the features, so the final position of the movement is fixed for the kinematical simulation by the coordinates of the part in the product situation.

The start position of the simulation is defined in all three axes either by the exploded view of the product or by a coordinate entered manually. The creation of the exploded model that does not represent the assembly sequence but a model without any contact between the different parts is a 
initial situation of the simulation. The exploded view can be generated automated by positioning the parts in consideration of the dimension of every part. Each component is placed on line with the same orientation of a special part and a connection to the coordinates of the component situation or in a right angle to this line. The decision between these two possibilities is also based on a collision check by the movement of the part in assembly situation in the possible directions.



Figure 2. Assembly Operation as semantic Information in Skelton Models

So the path is a straight movement to the component's position of the assembled product. That realises an automated joint process simulation with the lowest effort on the production system because there is no complex movement for the assembly system that increases the cycle time. Figure 3 illustrates the definition of the assembly direction by a collision check while dismantling the product. The movements of the parts can be modified manually to realise another movement to the component's position. But this possibility should be used only, if there is no other idea to assemble the product with straight movements.

Another requirement to reduce the number of possible assembly sequences and to achieve a cheap assembly is to fix moveable components at the assembly simulation. That means, that turnable components are handled as fixed components and rotations are not allowed during the assembly operation of different elements. E.g. the crankshaft does not rotate around its axis during the assembly of the different conrods and the pistons to realise an improved accessibility. 
The collision check is based on the automated design realisation of the rough geometry of the components which are given by the skeleton and function elements. The contour is established in the features, so e.g. a shaft is a rotation of a contour line around a defined axis to create a three dimensional body. This rough geometry of the parts is analysed along the joining movement whether there is a collision. The number of the assembly sequences by using the assembly graph must be reduced to minimise the simulation runs. For the assembly sequence the directed assembly graph is consulted and the basic part that takes the other components has to be determined.

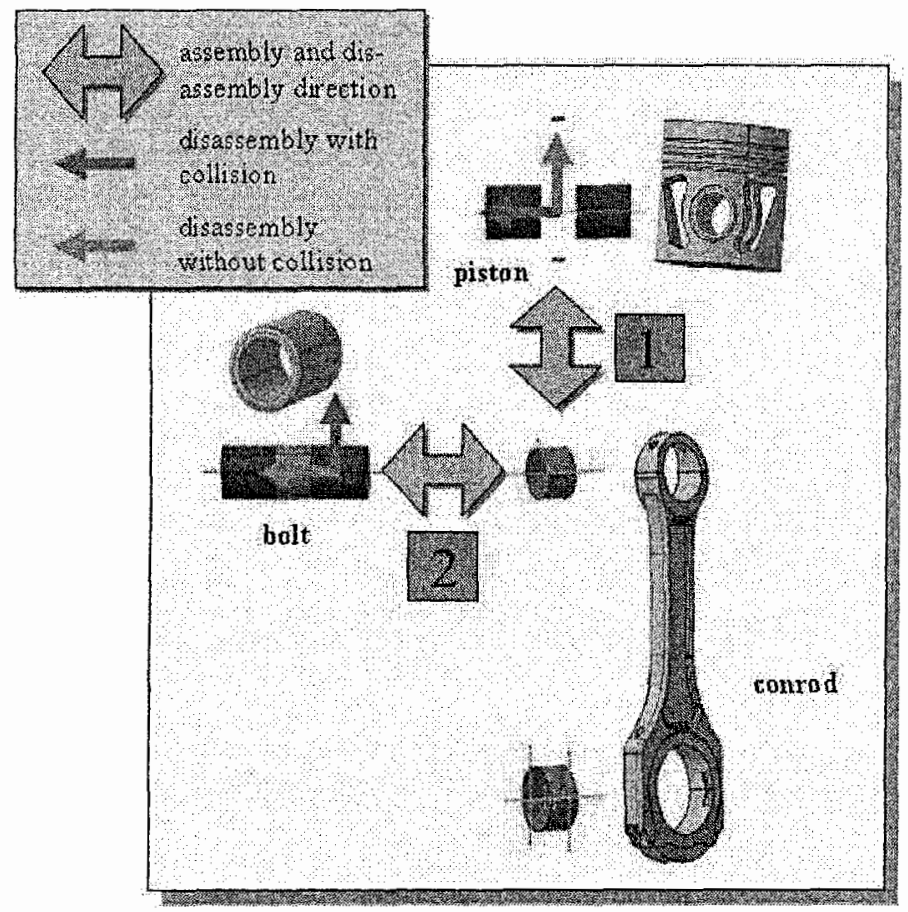

Figure 3. Definition of the Assembly Direction

The directed assembly graph is subdivided into assembly levels [11] in which, for different assembly levels, a defined order is represented. The order within an assembly level but not of the assembly levels themselves can vary. Concerning the assembly sequences it is important to define subassemblies as single components that expect only one assembly movement.

Simulations can help to find suitable sub-assemblies in a product model to group all components within the whole product model. The definition of 
the sequence of the assembly levels is followed by a simulation to check collisions. If there is a collision all assembly orders with the same assembly sub-sequence will be deleted. Therefore every collision minimises the number of assembly possibilities in a large number. The validity of the estimation of the assembly performance must be verified at certain stages to cause a protected model. Now the question can arise, why a planning expert should integrate the assembly simulation at such an early time of the development process. The answer to this question is very simple: Processing steps parallel to product design can be shown and checked by analysing the skeleton model. Such a development process helps to redesign with the consequence of a improved production of the components and a frictionless assembly of the product. It should be only the first step in digital assembly planning to protect the product model against collision, it is also important to have a look at the handling equipment to control its collision. Therefore the possible assembly sequences have to be enhanced with the handling equipment at certain areas of the product that have to be defined by the planning division. $[12,13]$

There are two approaches:

1. the use of the real geometry of the grippers

2. the use of a covering geometry which symbolizes the design room of a gripper that is not defined yet.

The expansion of the digital assembly model by the handling equipment is very important to estimate collisions of the equipment with the components or different tools with each other at simultaneous joint events because not only the components can collide during the assembly operation.

Handling equipment, mould cavity geometry or the holding appliances represent "direct" restrictions to the components to assemble the product. The gripper position [13] of each component can be defined as a feature in the product model. So, an automated insert of the real geometry or a place holder that represents the space of the gripper, can be installed in the skeleton model. If the position of the handling equipment is fixed the feature element can choose the best resource for the task without any collision. In this way, the product model is enhanced with the gripper information. The number of assembly orders is reduced by the collision check of the components too, so not all possibilities have to be evaluated.

In the first step of the assembly simulation task only the parts of the product should be simulated. So, it can be avoided to block too much disk space that reduces the calculation performance. Therefore a collision check of the components can be verified faster as an extended simulation model. 
The choice algorithm of a possible assembly sequence can run during the creation of the extended simulation model, so parallelisms in the work of one department are possible. After the extended simulation has shown possible assembly orders, this model should be enlarged again by enhancing the handling components and the other components with a direct connection. That way, a creation of a product-resource-model of the assembly system is achieved. An enhancement of the grippers is e.g. the resource "robot" that allows to analyse the working space and the complexity of the movement by joining the parts.

This analyse primarily supports the process planner in positioning the resources. One can imagine that to compare the different positions in different simulation runs to finding an optimised place for all resources to perform their work. The process planner must carry out restrictions to reduce the number of simulation runs, in order to get a better result in less time, e.g. layout restriction.

These three simulation tasks are shown in figure 4. The result is a whole production system simulation in the digital world. With the simulation of the resources the process planner provides the initial information for the control engineering. A control loop should also be integrated between the process planning department and the control department to optimise the production system regarding stability and productivity [14].

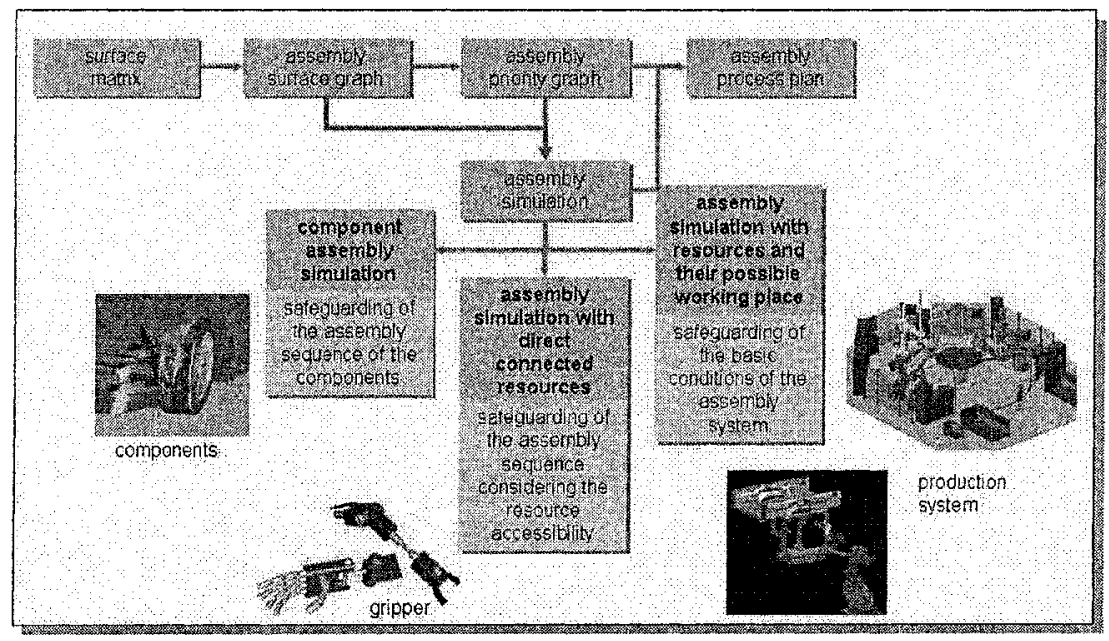

Figure 4. Three Simulation Tasks towards the Digital Model of the Assembly System

Starting with the simulation for an arbitrary assembly order the assembly priority graph can be created and detailed as a next step in the assembly planning process. The assembly priority graph has a dynamic link [15] to the 
product model which demands an update after product changes in which it is checked again whether the assembly assessment has been lost. This analysis primarily supports the process planner in positioning the resources.

This enhanced parallelisation of product development and production planning can avoid cost-intensive assembly processes by simple improvements in design. Another advantage of the new modelling and planning strategy is an interdisciplinary discussion platform for the departments to improve the transparency in product design and process planning as well as in resource planning. The process and resource information that does not influence the product are integrated in the process model [15]. It is important that there is a dynamical connection between the extended product model and the extended process model. Therefore, an information change that is represented in both models is interlinked with each other to realise an up-todateness. The digital copy of the production system can also serve as a test area for the control engineer to evaluate his programs and to make a comparison of the planned value and the calculated cycle time of each single assembly system unit.

After the test runs of the PLC based on the digital model a more robust start-up phase of the production should be ensured within the real factory. At the moment different activities in industries are established in this area of coupling digital and real factory.

Supporting this coupling both models have to be prepared optimally for each other to reach the aim with a minimum of work. Our approach of a gradual expansion of the assembly simulation is a support of the digital planning by an automated creation of kinematics simulation. Supporting routine activities the inhibition threshold for the use of such tools is considerably less. The planning department shall be able to comprehend the approach of the software because the tool shall not be understood as a black box with petitions and editions.

\section{SUMMARY AND OUTLOOK}

Standardisation of modelling with skeleton elements achieves a model of the product representing the functionality in a transparent way. Using feature technology in combination with the skeleton modelling approach reached the advantage of a well structured product tree and the other advantage of an easy handling by creating product variants. The product model is extended by the formation of feature combinations that enhance the product model with process and resource information through the whole product development process. In doing so, coupling of product design and 
production planning can be achieved. The department-related relevant data can be selected with different filter technologies.

For the assembly planning task opposite skeleton elements at the same position in the product model symbolise an assembly operation based on a contact surface of two parts. So, it is possible to deduce the assembly contact surface matrix and the assembly contact surface graph of the product model in early development phases.

In the next step the different assembly sequences will be tested automated by a collision check, and the best assembly sequence can be prepared in detail by the assembly planning department. The next step is an enhancement of the product model with direct connected resources to evaluate these sequences again. Then, the assembly model can be extended again with the whole resources to optimise their working position. The result is a digital model of the assembly system representing the initial data for the control department.

\section{REFERENCES}

1. VDI, VDI-Richtlinie 4499: Digitale Fabrik, Grundlagen (to be published)

2. Cuiper, R.; Feldmann, C.; Roßgoderer, U.: Rechnerunterstütze Parallesisierung von Konstruktion und Montageplanung. ZWF 91 7-8, pp. 338-341, 1996

3. Ehrlenspiel, K.: Integrierte Produktentwicklung. München, Hanser, 1995

4. Lindemann, U.; Reinhart, G.; Bichlmaier, C.; Grunwald, S.: PMM - Process Methodology for integrated design and assembly planning. Proceedings of the $4^{\text {th }}$ Design for Manufacturing Coference, Las Vegas, Vevade, USA, 1999

5. VDI, VDI-Richtlinie 2218: Feature-Technologie, 1999

6. Weber, C.: What is a feature and What is its Use? - Result of FEMEX Working Group I Proceeding of the $29^{\text {th }}$ International Symposium on Automotive Technology and Automation 1996, pp. 109-116, Florence, ISBN 0-94771-978-4

7. Bley, H.; Bossmann, M.; Zenner, C.: Flexible Process Models in Manufacuring based on Skeleton Product Models. Preprints of IFAC-MIM Conference on Manufacturing, Modelling and Control, Athens, Greece, 2004

8. Bley, H.; Bossmann, M.: Improyed Manufacturing Planning based on Localisation of Product Synergy Effects by the Use of Feature Technology. Proceeding of the $38^{\text {th }}$ CIRP International Seminar on Manufacturing Systems, Forianopolis, Bazil, 2005

9. Bär, T.; Haasis, S.; Verkürzung der Entwicklungszeiten durch den Einsatz von SkelettModellen und Feature-Technologie, VDI-Bericht Nr. 1614, Düsseldorf, Germany

10. Chaudron, V.; Martin, P.; Godot, X.: Assembly sequences: Planning and simulation assembly operations. Proceeding of the $6^{\text {th }}$ IEEE International Symposium on Assembly and Task Planning, Montreal, Cannada, 2005

11. Bley, H.; Bossmann, M.: Standardisierte Produktmodelle für die automatisierte Montageplanung Featurebasierte Montageplanung unterstützt den Simultaneous Engineering-Prozess, wt Werkstatttechnik - Ausgabe 09-2005, pp. 627-631, 2005

12. Bley, H.; Fox, M.: Entwicklung eines featurebasierten Konzepts zur Montageplanung, VDI Bericht Nr. 1171, Serienfertigung feinwerktechnischer Produkte - von der Produktplanung bis zum Recycling, pp 231-250, VDI-Verlag, Düsseldorf, 1994 
13. Dietz, S.: Wissen zur Auswahl von Montagemitteln, seine Aufbereitung und Verarbeitung on CA-Systemen. Dissertationsreihe Universität des Saarlandes, Lehrstubl für Fertigungstechnik/CAM, Schriftenreihe, Produktionstechnik Band 6, Saarbrücken, 1994

14. Reinhart, G.; Cuiper, R.: Planning and Control of Automated Assembly Systems. MEDVol.8, Proccedings of the ASME Manufacturing Science and Engineering Division, pp. 325-330, Anaheim, California, USA, 1998

15. Bley, H.; Bossmann, M.; Zenner, C.: Advances towards an Integrated Product and Production Development Process. Proceedings of 2. German - Israeli Symposium for Design and Manufacture - Advances in Methods and Systems for Products and Processes, pp. 129-137, Berlin, Germany, 2005 